\title{
REPRESENTAÇÃO DO CONHECIMENTO: HISTÓRIA, SENTIMENTO E PERCEPÇÃO
}

\section{REPRESENTACIÓN DEL CONOCIMIENTO: HISTORIA, SENTIMIENTO Y LA PERCEPCIÓN}

\begin{abstract}
Mário Caixeta - caimar@terra.com.br
Mestre em Ciência da Informação pela Escola de Ciência da Informação da Universidade Federal de Minas gerais (UFMG). Professor da Escola de Ciência da Informação da Universidade Federal de Minas Gerais
\end{abstract}

(UFMG)

Renato Rocha Souza - rsouza@eci.ufmg.br Doutor em Ciência da Informação pela Universidade Federal de Minas Gerais (UFMG). Professor Escola de Ciência da Informação da Universidade Federal de Minas Gerais (UFMG)

\begin{abstract}
Resumo
O artigo pretende evidenciar e desenvolver algumas idéias sobre aquilo que subjaz à representação do conhecimento, levando-se em consideração que a quase totalidade dos processos informacionais dependem de processos de representação. Pretende apresentar uma reflexão sobre alguns dos elementos que compõem o processo em questão a partir da análise das contribuições teóricas históricas sobre as formas humanas de representar o mundo em que vivem e seus sentimentos e percepções em relação a este.
\end{abstract}

\author{
Palavras-Chave \\ Representação do conhecimento. Processos \\ informacionais. Comunicação do \\ conhecimento.
}




\section{INTRODUÇÃO}

O artigo em questão se apresenta como um ensaio e pretende oferecer uma digressão sobre o tema da representação do conhecimento, abordando diversas facetas deste processo fundamental e tão caro à Ciência da Informação. Faz-se necessário, porém, dada a complexidade da tarefa que aqui se propõe uma declaração prévia de incompletude, uma vez que a exigüidade do formato do documento exige que diversos aspectos sejam tratados de forma superficial e ligeira. Espera-se, porém, que o documento em questão seja subsídio para alimentar as necessárias discussões sobre o assunto. Serão apresentadas diversas facetas do processo de representação, com a proposição em seguida de um esquema interpretativo e sumarizante de tal processo, confeccionado pelos autores. Ao final, faz-se menção ao contexto digital da representação, que introduz novas questões a área delineando seu caminho futuro.

Não seria exagero afirmar que a ciência da informação é, eminentemente, uma ciência da representação, e a grande maioria das atividades que desempenham seus profissionais gravitam em torno de sistemas de recuperação de informações. Em cada registro de conhecimento, em seus metadados, e em cada necessidade de informação, está implícita a necessidade de representação para que seja possível a comunicação de subjetividades.

O fenômeno da representação é tão antigo quanto qualquer forma de civilização. Talvez um dos trabalhos mais angulares de significados da nossa civilização tenha sido a representação dos seres, das coisas, idéias e fenômenos pelo alfabeto. Os levantamentos arqueológicos sobre a lingüística determinam que o primeiro alfabeto, base da nossa linguagem escrita ocidental, vem dos egípcios, em 4.000 AC (MAN, 2002). A forma mais próxima do que conhecemos hoje como estrutura de comunicação por palavras vem exatamente dos gregos, a partir do uso das duas primeiras letras, alfa e beta (CAGLIARI, 2007), que revolucionou a própria informação ocidental, exatamente pelo salto na sua representação.

O outro importante impulso na representação dos fenômenos da natureza e dos seres foi a construção do conhecimento matemático. Mesmo considerando outras formas de representar a quantidade, a matemática foi fundamental para estabelecer leis da natureza baseadas em símbolos que representassem a contagem e a maioria das leis de causa e efeito e outras relações que regem elementos da natureza, passíveis de comprovação por uma lógica 
científica e racional. Pode-se dizer algarismos representando uma lógica de que o conhecimento mais importante nesta ângulos, o que seria ponto de partida para área nasce também com os gregos a álgebra e a geometria. Os desenhos chamados pitagóricos, a escola de abaixo representam 3 números. Pode-se discípulos de Pitágoras. Já os algarismos, notar que o número dois contém dois conforme o representamos hoje, vieram ângulos, o número quatro contém quatro dos árabes. Os árabes criaram os ângulos e o zero não possui ângulo algum.
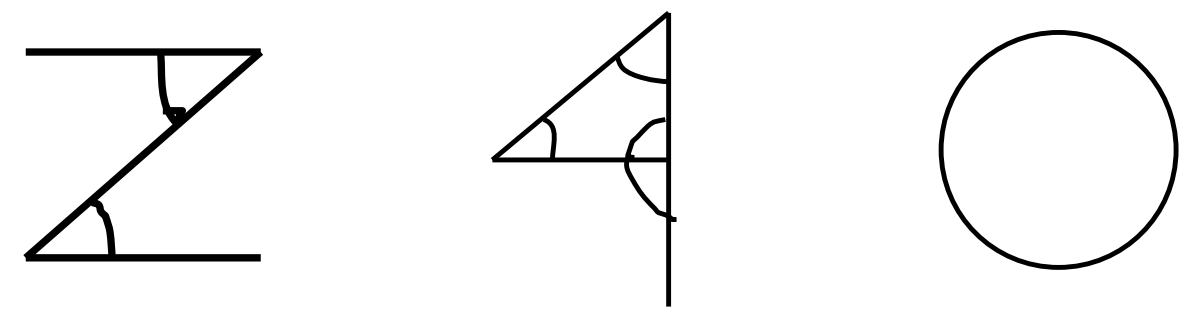

Figura 1 - representação de números como imaginada pelos árabes. Desenhos do autor

Fonte: Calandri (1491, p. 145) com a terminologia "Numeri in abaco scribendi" referindo-se aos algarismos arábicos.

Desnecessário dizer da importância da representação matemática do mundo, pela qual se tornou possível a evolução tecnológica, as tecnologias da informação e comunicação e os atuais sistemas de recuperação da informação. A Ciência da Informação, na grande maioria dos seus cientistas, admite que sua base teórica comece a emergir com a Teoria Matemática da Informação de Shanon e Weaver publicada pela primeira vez em 1948. Não obstante esta primeira teoria da informação refletir um viés da tecnologia de transmissão e uma visão fisicista, a matemática foi o instrumento utilizado por esses dois cientistas para tentar explicar 0 comportamento do seu ciclo de emissão e recepção. Curiosamente, os dois pesquisadores deram uma atenção especial aos problemas da interpretação, embora sob o ângulo da física. Para eles, a comunicação da informação trazia três níveis de problemas: I) problema técnico como transmitir com exatidão os símbolos da comunicação; li) problema de semântica -com que precisão os símbolos transmitidos transferem 0 significado desejado e lii) problemas de eficiência com que eficiência o transmitido afeta $o$ comportamento e a conduta do receptor, em relação à finalidade desejada e prevista. (SHANNON; WEAVER, 1975) O olhar desses autores sobre problemas da integridade da informação já demonstra a preocupação dos estudiosos com a representação do significado desde as primeiras buscas de uma teoria para o campo da informação. No caso de Shannon e Weaver a preocupação com a integridade da transmissão da informação 
pode ser expressa no conceito numa adaptação da chamada equação desenvolvido pelos dois, sobre fundamental da ciência da informação.

deformações da fidelidade, entendida no modelo como ruídos, ou "[...] alterações impostas ao sinal transmitido". (SHANNON; WEAVER, 1975, p. 8). Esta construção foi adotada como a nascente teórica do fenômeno da informação, e por não explicar totalmente 0 processo informacional, foi encarada por outros pensadores como uma teoria reducionista. $\mathrm{Na}$ verdade ela é o resultado da proposta dos dois cientistas a uma encomenda de origem militar do governo americano sob duas premissas: explicar o processo linear de transmissão da informação e orientar ações de como manter o máximo de fidelidade do seu significado transmitido até seu destinatário final. De fato, o modelo não considera os impactos sócios culturais e os de natureza subjetiva sobre o usuário da informação, mas já levanta a problemática da representação da informação e do conhecimento. É preciso, entretanto, ressaltar que esta teoria de base matemática, continua instrumento muito útil para a construção de sistemas de recuperação de informação.

A matemática também seria 0 instrumento científico utilizado na abordagem cognitiva, como um modelo de transferência de informação que foi representado por uma equação, ou função, por Brookes (apud CORNELIUS, 2002),

$$
K(S)+\Delta l=K(S+\Delta S)
$$

Onde se procura mostrar como um incremento de informação $(\boldsymbol{\Delta} /)$ pode afetar a quantidade de conhecimento possuído.

Ainda dos gregos proveio outra importante forma de representação. Falamos da mitologia que possibilitou aos homens a capacidade de representação dos sentimentos humanos vinculados às várias características das divindades do Olimpo: "Os gregos criaram seus deuses à sua própria imagem." (HAMILTON, 1992, p. 8). A mitologia helênica também deu a base simbólica para a maior parte do desenvolvimento simbólico da Psicanálise de Freud, que assim pode representar os fenômenos do consciente e do inconsciente - instinto, impulso e desejo (CHAUI, 1997). Em tempos do pós modernismo ou da "Era da Informação", vem a idéia da representação da informação e do conhecimento desenvolvida no chamado Mundo 3 de Popper, austríaco, considerado um dos mais influentes filósofos do século $X X$. Nesta teoria o mundo se dividiria em três mundos. O mundo 1 seria o lugar dos fenômenos e entidades do mundo real, da experiência direta. No mundo 2, os produtos dos estados mentais e do intelecto humano, idéias e percepções. No mundo 3 estariam as representações, ou 
seja, as "materializações" do mundo 2 nos suportes do mundo 1.

Partindo dessas considerações ilustrativas do desenvolvimento da representação humana, vamos examinar algumas das características próprias dos seres humanos, capazes de interferir na representação da informação e do conhecimento, tomando como base 0 processo de interpretação dos fenômenos e das coisas reais. O exame de algumas dessas qualidades intrínsecas ao homem pode ajudar a compreender a complexidade e a relatividade da própria representação. A maioria das idéias e conceitos sob a égide desses fatores que afetam a representação do conhecimento está apoiada nos conceitos de Mora (1996), Chauí (1994; 1997) e Abrão (1999).

\section{QUE É REPRESENTAÇÃO}

Filosoficamente, a representação refere-se aos "[...] diversos tipos de apreensão intencional de um objeto" (MORA, 1996, p. 629). Aristóteles já se referia a ela como um fenômeno da fantasia (intelectual ou sensível). Os estóicos a viam como impressão. Descartes como imaginação. Spinoza distinguia-a entre apreensão sensível e conceitual e Schopenhauer referia-se à "[...] forma do mundo dos objetos como manifestações da vontade [...]" (MORA,
1996, p. 630). Para Mora o termo é ambíguo, especialmente quando se trata de esclarecer a natureza e as formas do conhecimento do mundo pela epistemologia e a psicologia, e na relação entre essas duas. $\mathrm{Na}$ psicologia, a representação pode ser vista de quatro formas:

1 Como objeto efetivamente presente, equiparada à idéia de percepção;

2 Como reprodução na consciência de percepções passadas, o que poderia ser entendido como memória ou recordações;

3 Como antecipação dos acontecimentos futuros, baseada em percepções passadas, seria a imaginação;

4 União na consciência de várias percepções não atuais e nem passadas ou antecipatórias, que tanto pode no levar a idéia da imaginação como da alucinação.

Ainda no campo da psicologia admite-se a representação baseada no predomínio de um dos sentidos humanos acústica, ótica, visual, etc., além de representações conceituais, afetivas e volitivas.

\section{A despeito de tantas} interpretações, representação é o ponto crucial do processo informacional, pois cabe a ela fazer a "tradução" do saber 
sobre os seres e as coisas do mundo real para o usuário final da informação, e é através dela que se fazem as translações entre os três mundos Popperianos. O usuário da informação, com diferentes níveis de cognição, fidelidade e neutralidade possíveis, tem acesso ao conhecimento sobre o mundo físico e das idéias, através de seus elementos constitutivos (documentação), conectados pela eficácia dos sistemas de recuperação de informação. Estes, por sua vez, empreendem tarefas sociais, técnicas e epistemológicas, para propiciar uma navegação entre os vários graus de representação no sentido de oferecer o máximo de informação relevante de acordo com a demanda do usuário. Em todas as suas fases, o ciclo informacional tem que lidar, além de questões meramente ligadas às implementações tecnológicas, com as restrições e distorções impostas pela subjetividade e contaminação oriundas do fenômeno hermenêutico e dos paradigmas socioculturais. É a diversidade inerente ao contexto dos que interpretam 0 conhecimento, nos diversos estágios em que ele é processado. Ainda no âmbito dos sistemas de recuperação de informações, destacam-se as dimensões ontológicas (representação advinda da percepção das coisas do mundo) e epistemológicas, onde o objeto são as representações primárias que redundam em índices, catálogos ou outros surrogates. (ALVARENGA, 2003).

Sem nenhuma pretensão de esgotamento, analisar-se-ão alguns desses fatores principais que afetam a representação, à luz de conceitos da filosofia, num esforço de compreensão maior do papel da representação no conhecimento humano. Serão exploradas algumas das facetas do processo, como: sensação e percepção; precipitação e prevenção; subjetividade e grau de consciência; memória, imaginação, linguagem, mito e finalmente ética e moral. Estes aspectos podem ser tomados isoladamente, mas ganham unidade quando analisamos a complexidade da função básica de representar, como subsídio à construção de acervos informacionais e como processo básico na construção do conhecimento humano.

\subsection{Sensação e Percepção}

O chamado conhecimento sensível é sinônimo de conhecimento empírico ou experiência sensível e ele se manifesta em duas dimensões: a sensação e a percepção. A sensação fornece aos nossos sentidos as qualidades exteriores e interiores dos objetos e seus efeitos internos sobre 0 ser humano. São exemplos cores, sabores, sensações térmicas, etc. Chauí (1997 p. 120) diz que "Sentir é algo ambíguo, pois o sensível é, ao mesmo tempo, a qualidade que está no 
objeto e o sentimento interno que nosso corpo possui das qualidades sentidas". A representação dessas sensações é feita pelo vínculo com determinado objeto concreto: o mar está azul, a rosa é perfumada, a tarde está gelada. Ou seja, a nossa sensação é feita mais com a integração a objetos complexos e amplos do que a simples sensação da qualidade pura e isolada. Daí vem o conceito de percepção, que pode ser definida como "a síntese das sensações" (CHAUÍ 1997, p. 120). Para os empiristas, a sensação e a percepção dependem das coisas e estímulos externos que atuam nos nossos sentidos (cor, sabor, odor). A percepção é ligada ao objeto qualificado por esta sensação. Há inúmeras sensações e elas são unidas intelectualmente pela percepção, que neste conjunto formam o conhecimento (o céu azul, o sangue vermelho, água do mar salgada). Hume (apud MORA, 1996, p. 537) dividiu todas as percepções em "impressões" e "idéias". Segundo ele as impressões são as "[...] nossas percepções mais vívidas, quando ouvimos ou vemos, ou sentimos, ou amamos, ou odiamos, ou desejamos, ou queremos". A idéia, no seu conceito "[...] são as tênues imagens daquelas impressões ao pensar e ao a raciocinar [...]". Vale mencionar, ainda, o conceito de "percepções extra-sensoriais", aquelas que vão além dos sistemas de referências psicológicos e neurofisiológicos e que muitos atribuem às representações estimuladas por drogas.

Ao entendermos o sentido filosófico de sensação e percepção, pode-se compreender sua influência na representação da informação e do conhecimento produzida. A partir de sua gênese, transmissão e recepção, a informação - dentro do seu ciclo clássico de registro, organização e recuperação desenvolve possivelmente um somatório quase inacreditável de diversidades de representações para 0 ser humano contidas no seu significado final. Afetam sobremaneira a sensação e percepção a precipitação e prevenção, como se vê em seguida.

\subsection{Precipitação e Prevenção}

Descartes formulou duas hipóteses para explicar o erro humano. A primeira é a precipitação, ou seja, a atitude que adotamos ao sermos levados facilmente pelas opiniões e conceitos alheios, sem o devido cuidado de fazer uma verificação da sua veracidade ou consistência. A segunda é a prevenção, que é fruto da velocidade com que emitimos julgamentos sem dar tempo a uma melhor reflexão ou investigação sobre sua real veracidade. É o que podemos chamar de preconceito, postura que nos afasta do pensamento e da investigação, um dos grandes inimigos 
da ciência. Origina-se do nosso conhecimento sensível, da imaginação, da linguagem e da memória. De certa forma, podemos situá-la como algo próximo dos nossos impulsos afetivos, sentimento que no entender de Boson (1996 p. 86) "[...] é o instinto, conduta do ser vivo, expressão de estados internos que tanto pode ser explicado fisiologicamente como psicologicamente". Esses dois sentimentos humanos, especialmente o primeiro, comprometem a representação da informação e do conhecimento e do conhecimento. Seus efeitos, contudo, podem ser atenuados pelos cuidados em lidar com certos sentimentos iniciais na hora de buscar uma melhor representação informacional. A realidade mostra inúmeras concepções preconceituosas e precipitadas por diversas razões, inclusive pela velocidade e urgência em darem-se determinadas respostas ao usuário. Além do mais, constatado um erro nesta representação, haverá uma dificuldade imediata nas reparações conceituais, dado o alto grau de velocidade no tempo e no espaço da disseminação que os sistemas de informação apresentam hoje. Não menos importantes, também afetam a percepção a subjetividade e grau de consciência, apresentados a seguir.

\subsection{Subjetividade e Grau de Consciência}

A subjetividade é a constituição do
"[...] eu, pessoa, cidadão e sujeito, que compõem a consciência ativa, o local da razão e do pensamento. É aquela capaz de ter uma identidade consigo mesma, ter virtude, direitos e verdade" (CHAUI, 1997, p.119). Ao falar de consciência, é preciso dizer dos seus diversos graus, que seriam:

1 Consciência passiva - estágio do qual se tem uma vaga e confusa percepção de nós mesmos e do que se passa em nosso entorno. Exemplos: os devaneios, momentos que precedem o sono ou na fase da criança muito jovem ou dos idosos.

2 Consciência vivida, mas não reflexiva - é a chamada consciência afetiva. Sua principal característica é ser egocêntrica, ou seja, perceber os outros e as demais coisas, a partir de nossos sentimentos com relação a eles. Neste grau de consciência não conseguimos separar o eu do outro, ou o eu e as coisas. É uma dimensão traduzida por sentimentos, amor, ódio, cólera, alegria, tristeza, etc.

3 Consciência ativa e reflexiva- a que reconhece a diferença entre 0 interior e o exterior, ente si e os outros, entre si e as coisas. É o grau que permite exatamente a subjetividade dentro das 
modalidades: eu, pessoa, cidadão e sujeito. Isto é o que se denomina de consciência intencional ou intencionalidade.

A consciência realiza atos (perceber, lembrar, imaginar, refletir, etc.) ou significações (o percebido, o lembrado, o imaginado, o refletido, etc.). Portanto, a nossa capacidade de representar está exatamente nas significações da consciência ativa e reflexiva, o que, como seres humanos, nem sempre está presente. Daí sua influência, igualmente, nas representações de conteúdos informacionais. Tão importante quanto o grau de consciência, porém, é a memória, capaz de reter as impressões no sentido de criarem-se as representações.

\subsection{Memória}

A memória é um chamado ao passado, a capacidade do ser humano de reter certos acontecimentos na mente, não deixando ocorrer sua destruição pelo esquecimento total. É a garantia da nossa própria identidade (PROUST apud CHAUÍ, 1997). A memória seria uma forma de percepção interna, também chamada de introspecção e é interior ao sujeito do conhecimento. Também podemos evocar este conceito dentro da perspectiva do coletivo e do social. Os gregos a representavam na mitologia pela deusa Mnemosyne, a mãe das musas, protetora das artes e da história. A memória está visceralmente ligada ao tempo ou da sua percepção de algo que passa. Para Chauí (1997) existem seis grandes tipos de memória:

1 Perceptiva ou reconhecimento (reconhecer pessoas, coisas e lugares)

2 Memória-hábito, (nossos hábitos e repetições de ações cotidianas);

3 Fluxo de duração pessoal, (individualizada e vinculada a nossa dimensão afetiva ou aos nossos conhecimentos ao longo da nossa história como ser);

4 Memória social ou histórica, adquirida via mito, relatos, registros, documentos, monumentos, datas e nomes de pessoas, fatos, lugares que possuem significado para a vida coletiva. À exceção dos mitos, todos os demais são fatos objetivos, portanto documentados.

5 Memória biológica da espécie, gravada no código genético.

6 Memória artificial das Tecnologias de Informação e Comunicação e demais artefatos nesta linha, que se baseiam numa representação do cérebro humano.

O próprio sentido dado ao campo da memória, o fluxo temporal e os significados subjetivos e objetivos que impregnam 
nossas ações e emoções já demonstra a sua contribuição para a construção da representação da informação e do conhecimento. Há uma influência no indivíduo (das três primeiras e da memória biológica) e uma no caráter coletivo, a memória social. Todas essas tem papel reservado na ação de representação da informação e do conhecimento, seja olhando pelo lado de quem interpreta e registra fatos, seja pelo lado do usuário final que a recebe. É o que chamaríamos de contexto. A memória artificial, por si só, é uma representação restrita da realidade psíquica e física do homem. Em relação ao conhecimento humano é importante a fala de Chauí (1997, p. 130) sobre o "Reconhecimento e produção do dado percebido, experimentado ou conhecido numa imagem que, ao ser lembrada, permite estabelecer uma relação ou um nexo entre o já conhecido e os novos conhecimentos". Aristóteles, por sua vez, dizia, quando escreveu sobre a metafísica: "É da memória que os homens derivam a experiência, pois as recordações repetidas da mesma coisa produzem o efeito duma única experiência." (apud CHAUÍ, 1997, p. 130). Aquele a quem foi reservado a função de construir a representação do conhecimento deveria considerar este ensinamento como uma das premissas para interpretar e dar significado ao fenômeno informacional.
Seguindo o caminho traçado, tratarse-á da imaginação, matéria prima para as construções intelectuais humanas que não advêm das percepções externas.

\subsection{Imaginação}

Se "A memória é retenção, a imaginação é protensão." (CHAUÍ, 1997, p.130). Na filosofia, a imaginação é considerada como um objeto percebido que permanece retido em nossa consciência. Para os empiristas ela é o reflexo mental das nossas percepções ou nossas impressões. Num determinado senso, a imaginação seria aquilo que percebo, mesmo com o objeto não estando fisicamente presente. Alguns filósofos a consideravam como uma forma enfraquecida da percepção. A imaginação seria a reprodutora da percepção, quando estamos falando de conhecimento e, de forma indireta, a reprodutora da percepção, no campo da fantasia. Isso pode ser ilustrado, exatamente pela capacidade dos artistas em trabalhar objetos já conhecidos e que podem ser concebidos em uma nova representação. Por exemplo: o centauro seria a soma da imagem conhecida de um cavalo (o corpo) e a cabeça humana. Daí certa confusão entre imagem e imaginação, ambos com a mesma raiz morfológica. Em se tratando de imagens, umas se referem a objetos externos a nós, outras à nossa consciência. A imagem 
pode ser um símbolo: p. ex, a cruz suástica traz a lembrança imediata do nazismo; uma metáfora: sua vida é um mar de rosas; uma ilustração: signos (símbolo de estacionamento proibido), etc. $\mathrm{O}$ que se tem de comum nessas configurações de imagens é que quase nunca correspondem, materialmente, à coisa imaginada. É através da imaginação que lidamos com a ausência e a inexistência. Chauí (1997) aponta cinco tipos de imaginação:

1 Reprodutora propriamente dita (que forma a imagem a partir da percepção ou da memória);

2 Evocadora (tem um significado afetivo, tornando presente o que está ausente);

3 Irrealizadora (a que coloca outra realidade, individualizada, é sonho, é devaneio, tem um toque de mágica);

4 Fabuladora (características do coletivo, do social, criadora de mitos e lendas e fortemente vinculada com a interpretação de fenômenos como a morte, por exemplo).

5 Criadora (dos artistas, dos cientistas, dos filósofos, onde se encontram elementos da afetividade, intelectualidade $e$ cultura). Este tipo de imaginação talvez seja o mais completo, pois parte das percepções, da memória das idéias existentes e do conhecimento humano e é apoiada por todos os demais tipos de memórias.

Para o conhecimento humano, a imaginação traz um lado altamente positivo e outro potencialmente danoso. No primeiro caso ela é fonte e suporte à criação de conhecimentos e desenvolvimento de experimentos e, em especial, uma das indutoras das inovações tecnológicas, por exemplo. Pelo lado negativo ela pode ser altamente dissimuladora e falsificadora da verdade, desviando o ser da realidade (quando ele a deveria ter como referência). Este desvio da realidade, também pode ser entendido como imaginário. Muitas vezes nos referimos ao imaginário popular, para dizer das crenças e mitos de uma comunidade ou cultura, distantes do quadro real. Quando o imaginário é social, configura-se a ideologia. Portanto, o papel da imaginação na vida do indivíduo e de uma coletividade é fator preponderante na representação de informação ou conhecimento, seja pelo que ela influencia na interpretação, seja pelo que ela orienta a eficácia desta representação, por parte de quem registra a informação, dentro do seu contexto sociocultural. Mas a comunicação interpessoal da representação depende do próximo 
assunto: a linguagem.

\subsection{Linguagem}

Aristóteles considerava o homem como um animal político, porque somente ele tem o atributo da linguagem para se comunicar (CHAUI, 1997). Para Rousseau a palavra é o elemento que distingue homens e animais e as nações entre si. Ela nasce de uma necessidade fundamental do homem em comunicar-se. Hjelmslev, um estudioso da lingüística dizia que o homem é inseparável da sua linguagem que o acompanha em todos os seus atos. A palavra grega mythos significa narrativa e, portanto linguagem. No dizer de Chauí (1997, p. 138) é "[...] através das palavras que os seres humanos organizam a realidade e a interpretam". $\mathrm{Na}$ outra dimensão a linguagem era representada pelos gregos pela palavra logos, que significava a palavra racional do conhecimento real (daí a lógica). Nesta concepção ela se refere a conceitos e idéias. Surge, assim, o confronto da linguagem em dois registros opostos: por um lado, ela expressa o ritual, o solene, o mágico, o religioso e o artístico (mitos),que serão detalhados na seqüência, e, por outro, a palavra científica, técnica, racional e conceitual. E, para muitos, é na separação dessas duas dimensões que surge a ciência, que desassocia toda a explicação que vem do primeiro registro de mythos. A filosofia e a lingüística exploram várias definições de linguagem e elas são, em resumo:

1 como sistema - é totalmente estruturada, com princípios e leis próprias;

2 sistema de sinais ou signos - é um tipo especial de objetos, os signos, ou objetos que indicam outros, designam outros ou representam outros;

3 indicadora de coisas - (função indicativa ou denotativa que apontam para as coisas que significam);

4 função comunicativa - é instrumento de relacionamento de uns com os outros, permitindo a argumentação, o diálogo, a persuasão, o amor, o ódio, etc,

5 expressão do pensamento - é o sentido de conotativa, ou seja uma mesma palavra pode assumir sentidos ou significados diferentes.

A corrente filosófica do positivismo lógico, distingue dois tipos de linguagem: a lógica - formalizada, mais pura (com enunciados das linguagens científicas e filosóficas), inspirada na matemática e na física e a natural - a que usamos todos os dias, imprecisa, porque comporta sentimentos afetivos, volitivos, perceptivos e imaginativos. Os sistemas de recuperação de informação utilizam-se, 
sobretudo, do primeiro tipo para literatura. Pertence ao campo do simbólico, representar a informação, mas ganha portanto é pura representação. A notoriedade a corrente de pesquisadores que começa a estudar mais profundamente a linguagem natural. Ou seja, "[...] as potencialidades intratextuais da linguagem natural automatizar e melhorar as tarefas de indexação, organização e recuperação das informações." (SOUZA, 2005, p. 6). A informação é influenciada pela linguagem ao ser representada e a usa como instrumento de sua expressão e inteligibilidade, por ser um dos mais profundos sinalizadores da diversidade cultural do homem no tempo e no espaço.

\subsection{Mito}

Para Hamilton (1992) os mitos representam a ciência antiga, uma forma de o homem explicar o sentido simbólico do que percebia e via em torno de si. Para os gregos, como vimos, o mythos assumia a dimensão de linguagem. Para Mora (1996) é uma alegoria que comporta duas faces: o fictício e o real. Entende-se como fictício o fato que não ocorreu da forma que a narração descreve como real. O mito é como se fosse um relato que pudesse ter ocorrido se o narrado coincidisse com o paradigma da realidade. $O$ pensamento mítico se contrapõe ao pensamento lógico e é através do primeiro que se expressam as formas humanas de conhecimento nos campos da religião, das artes e da antropologia social mostra que nossas sociedades convivem, simultaneamente, com o conceitual e o mítico, na medida em que a imaginação social utiliza-se do mito para "converter", em forma mais inteligível, os conceitos científicos e filosóficos. A outra linha origina-se dos estudos neurológicos e admite haver no cérebro humano duas partes ou hemisférios: num deles se localiza a linguagem e o pensamento simbólico e no outro a linguagem e o pensamento conceitual. Segundo Chauí (1997) são três as características principais: função explicativa (o presente explicado por alguma ação passada); função organizativa (como organizador das relações sociais, legitimando um sistema social complexo de proibições e permissões) e função compensatória (ao narrar certas passagens do passado, que é negação do que acontece no presente, o ser humano compensa a frustração pela perda ou dá a ele a garantia de que o erro passado foi corrigido e haverá uma certa estabilidade e regularidade na natureza e na vida em comunidade).

Entender a função do mito é um caminho para compreender o alcance e as restrições da representação da informação e do conhecimento, ela mesma um grande veículo de disseminação mitológica, um 
instrumento da linguagem e do discurso. dos corpos (nascimento e morte de coisas Mas os mitos podem ajudar a melhorar a da natureza e do homem). Assim, representação de um conhecimento, se o filosoficamente há quatro causas: material registro for feito considerando uma leitura adequada do usuário na sua fase de recuperação da informação.

Assim como o mito, a ideologia, tratada a seguir, oferece obstáculos à representação ideal, tanto utópica quanto desejada.

\subsection{Ideologia}

Um dos fatores que mais interferem na representação é, sem dúvida a ideologia. Diversos aspectos envolvem esta característica do ser humano pensante e tem aspectos multidisciplinares, mas aqui abordaremos apenas sua influência na representação. No essencial, sabemos que as primeiras idéias de ideologia vieram de Sócrates, com a sua lei das quatro causas. Resumidamente, ela buscava explicar o movimento das coisas e dos seres. Eram quatro movimentos básicos: I) a mudança qualitativa de um corpo qualquer (a semente que se transforma em árvore, a célula que se transforma em tecido, etc.); II) a mudança quantitativa de um corpo qualquer (a reprodução celular, por exemplo); III) a mudança de lugar ou locomoção de um corpo qualquer (a queda de uma folha da árvore, um objeto levantado por uma ventania, etc.) e IV) a geração e corrupção (o tijolo que seria a causa material de uma parede), formal (a maneira como uma parede é construída, dá-se pela forma do tijolo), motriz ou eficiente (porque a parede foi construída daquela forma pelo pedreiro) e a causa final (a finalidade porque aquela parede foi construída). As relações entre essas causas na natureza explicam tudo o que existe, a forma como o mundo existe e se modifica e a finalidade ou o motivo pelo qual existe. Feita a conexão com os movimentos sociais da humanidade, as causas poderiam explicar a ideologia dominante. Augusto Comte (apud CHAUI, 1994) definiu a ideologia pelo lado da atividade filosófica e científica a partir das idéias como campo de observação das relações entre o corpo humano e o meio ambiente. Trata-se de uma estrutura baseada, principalmente em sensações e por um conjunto de idéias de uma época, uma espécie de "opinião média" do pensamento existente num determinado espaço temporal. Löwy (2003, p.15) faz interessante análise das concepções deste termo, abordado por diversos pensadores mais modernos e ele mesmo dá a sua visão: "[...] todos aqueles conjuntos estruturados de valores, representações, idéias e orientações cognitivas." Assim ele introduz um debate sobre a visão social do 
mundo, a partir de uma dicotomia entre a ideologia e as visões utópicas.

Por outro lado, pelo conjunto de idéias de uma época, a ideologia pode ser considerada uma espécie de "opinião média" do pensamento existente numa determinada época. Para Durkheim, a ideologia é fruto da sociedade que não respeita os critérios de separação entre o sujeito do conhecimento e o objeto do conhecimento, ou seja, aquilo que garante a objetividade e a neutralidade do cientista. Marx não separava a produção das idéias, das condições sociais e históricas nas quais elas são produzidas. E é esta separação o que ele caracteriza como ideologia. Para ele, enquanto houver homens, a história da natureza e a história desses homens se condicionarão mutuamente (materialismo histórico). Podemos sintetizar o que seja a ideologia utilizando parte da definição de Chauí. A ideologia vem do "[...] senso comum social como resultado de uma elaboração intelectual sobre a realidade feita pelos pensadores ou intelectuais da sociedade, que descrevem e explicam o mundo, a partir do ponto de vista da classe a que pertencem e que é a classe dominante de sua sociedade." (CHAUI, 1997, p. 174). Adotando, simplesmente, que a ideologia é um conjunto sistematizado de idéias que orienta e domina um modo de ver as coisas, independente de qual seja o campo do conhecimento humano, é fácil perceber como ela pode afetar a representação. Ou, ainda, que a representação pode ser um resultado objetivo da ideologia de quem a fez. Em outras palavras, a tentativa de representação mais fiel possível de uma informação, estaria condicionada à visão de Durkheim, submetida a toda a neutralidade possível e desejável de quem observou o fenômeno, vai registrá-lo e transmiti-lo. Mais que um desafio, parecer ser utópico, pretender a integridade da informação e sua separação das idéias impregnadas por quem a manipulou.

Encerrando este pequeno ciclo, são discutidas brevemente as questões éticas e morais, na forma como afetam a representação.

\section{9 Ética e Moral}

Filosoficamente, o espírito é a razão que se materializa na inteligência. $O$ espírito atua em três dimensões:

1 Noético - é o campo dos princípios lógicos, dos juízos conduzidos pela lógica;

2 Poético - voltado para as ações de construção e criação;

3 Ético - é o campo do juízo de valor e a moral.

A origem é a palavra do grego ethos e que significa costume, hábito. $\mathrm{O}$ conceito evoluiu e passou a identificar-se, cada vez mais, com a moral. A ética deve a 
Kant uma grande transformação do seu não é só o ser cognoscente do paradigma conceito original. Ele procurou formular cognitivo, mas inteiramente mergulhado uma ética formal e calcada no rigor. Mais num novo paradigma dito social, que recentemente Findlay (apud, MORA 1996) abrange fundamentalmente seu contexto destacou que a ética não pode se sócio-cultural. Ele se refere a uma desenvolver sem uma teoria voltada ao linguagem ideal para representar o juízo de valor. Os juízos éticos de valor são também normativos e enunciam o que deve ser sobre nossos sentimentos $e$ conhecimento, que poderia considerar uma base de dados de caráter polissêmico ou mesmo polifônico.

ajuda a determinar o bem, o mal e o que é felicidade, por exemplo. Em decorrência, são esses os princípios que determinam que sentimentos, intenções e comportamentos devem ser condenados ou considerados incorretos diante do ponto de vista da moral. É a essência da nossa base legal ocidental. $O$ senso $e$ a consciência moral são inseparáveis da vida cultural e por isso mesmo, padrões éticos acabam influenciados no tempo e no espaço. Daí o enorme impacto na representação da informação e do conhecimento dentro de determinados limites sócio culturais. Aliás, conforme já chamava atenção Capurro (2003), o sujeito

\section{O CICLO DA REPRESENTAÇÃO}

Após a apresentação de alguns dos diversos fatores que influenciam as questões representacionais, pretende-se contribuir com uma síntese. A figura 2, desenvolvida por nós, procura mostrar as relações que se estabelecem a partir da necessidade da interpretação do conhecimento humano numa visão sistêmica, permeada pelas abordagens dos diversos campos de estudos vinculados à construção do ser humano como um indivíduo social. 


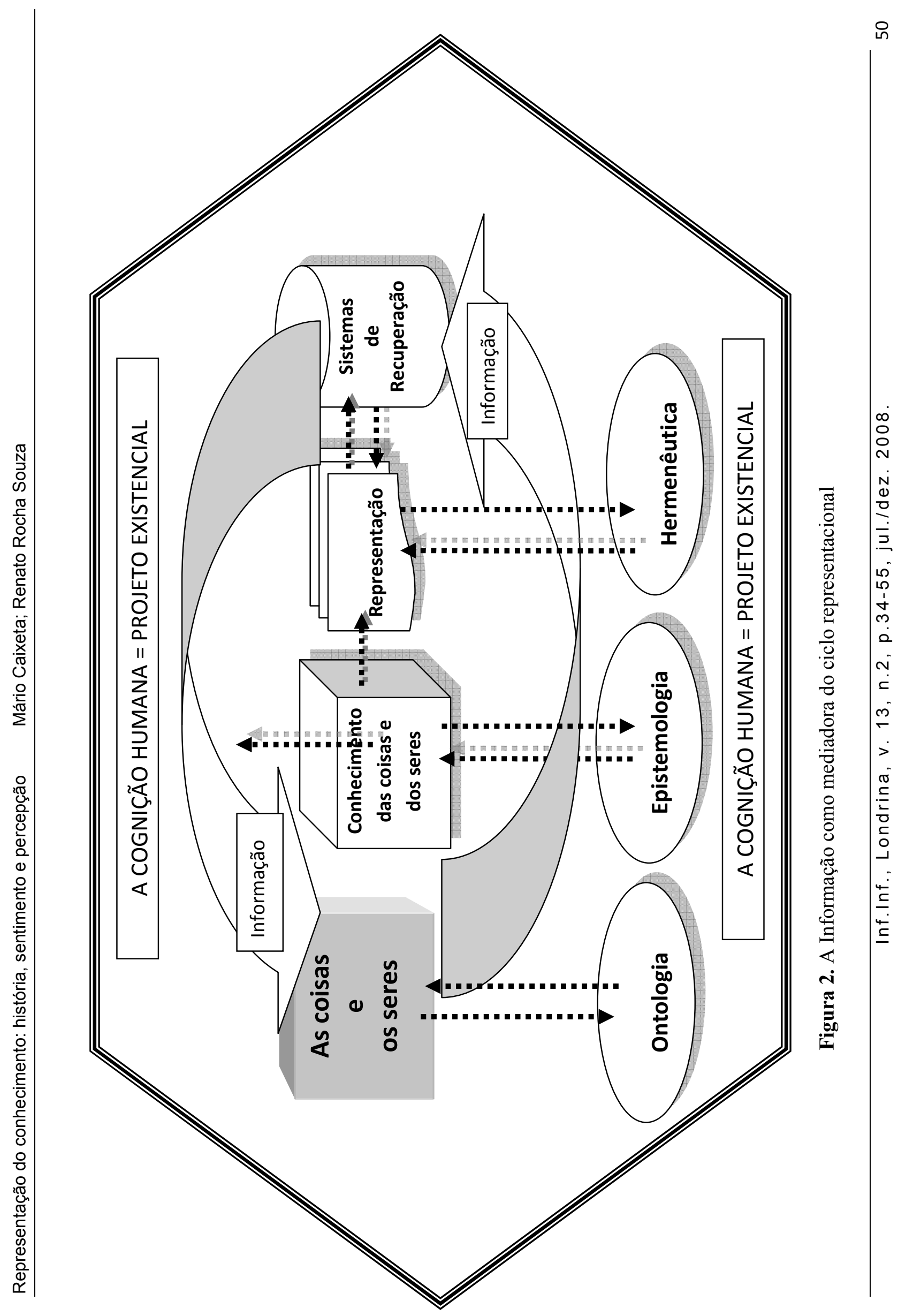


A elaboração deste modelo inspira-se nas idéias do alemão Heidegger, um dos pais do existencialismo que sintetiza seu raciocínio a partir do termo em alemão Dasein, que segundo Mora (1996, p. 256), poderia ser traduzido filosoficamente como "do ente humano para o ser". Para Heidegger dasein não é algo (o ser) que já é, mas que será. Em outras palavras, o homem é um ser em construção, o "sendo". E como tal, um projeto existencial. Nas palavras de Mora (1996, p. 261) "O homem não é, pois, nenhuma substância suscetível de ser determinada objetivamente. Seu ser é constituir-se a si mesmo." Sendo um ser construído ele é feito de símbolos e usa da simbologia para gerar e adquirir conhecimento. Daí resulta a idéia de que a construção do ser humano no seu dia a dia existencial é constituída da essência de seu progressivo autoconhecimento e do conhecimento vinculado, inexoravelmente, a informação e ao seu contexto.

Como se pode notar na figura, o aspecto comunicacional da informação que suporta todo o processo da cognição humana de representação do conhecimento, desde a observação do conjunto ontológico dos seres e das coisas - a sua representação (codificação), até seu armazenamento em qualquer um dos artefatos informacionais disponíveis. Desta forma, pode ser então recuperada por usuários - insumos fundamentais do "seu" projeto existencial - e ser reutilizada. A informação realiza seu caminho perene, fornece e dá contorno à cognição humana, cumprindo, assim, um ciclo dinâmico de representação, influenciando e sendo influenciada pelo contexto por onde trafega.

A base deste ciclo constitui-se de alguns campos das ciências que ajudam o homem na busca da verdade ou da compreensão da realidade, especialmente nos fenômenos sociais, dentro dos quais a informação é o agente e o conhecimento é o produto: a ontologia, a epistemologia e a hermenêutica. E na modulação causada pela plenitude dos aspectos cognitivos humanos, se incorporam os fatores sensação e percepção; precipitação e prevenção; subjetividade e grau de consciência; memória, imaginação, linguagem, mito, ética e moral, como apresentados no contexto deste trabalho.

A ontologia, que Aristóteles a definia como a primeira filosofia, também incorpora o conceito de metafísica, que é muito contraditório na literatura. Kant a denominou "o estudo dos conceitos" e Heidegger aquele campo da ciência que tem como missão primeira "a constituição do ser e da existência". A idéia mais geral é de que a ontologia é a concepção do universo de todos os seres que têm uma natureza comum e cujas características 
poderiam ser inerentes a todos e a cada um deles (CHAUI, 1997).

No campo da epistemologia, a representação assume dois sentidos principais: I) como conteúdo mental, o que Ihe confere um caráter subjetivo e particular e II) aquilo que se representa no ato de representar, como objeto intencional deste ato. Esta última forma, adverte Mora (1996), é uma idéia um pouco perdida na modernidade. Kant usou o termo alemão Vorsterllung, que poderia ser a tradução da representação no sentido mental, mas que outros autores, dentre os quais Wittgenstein preferia ao vocábulo Darstellung, que tem um sentido mais de modelo, plano ou esquema. Enquanto a primeira tem uma acepção mais subjetiva, a segunda é mais voltada para o formal, o objetivo. Alvarenga (2003, p. 5) trata o processo da produção de registros do conhecimento como "[...] um produto final, um conhecimento sobre a coisa, conhecimento que forma o campo que a filosofia denomina de epistemologia". Como a autora fala da representação primária - conceitos sobre os seres, as coisas e representação secundária - a constituição desses conceitos em itens que genericamente poderíamos chamar de "documentos", o objeto primeiro da gênese da Ciência da Informação.

A Hermenêutica, no entendimento de Gadamer (2001) se concebe a partir de uma forma dialética entre a ontologia da compreensão e os métodos rigorosos das ciências humanas que buscam uma explicação da realidade, num trabalho de estruturação da obra (a busca do sentido) e a projeção externa de si mesma (a referência). É como Platão a descrevia " $A$ explicação da diferença" (MORA, 1986, p. 331). E Gadamer deu-lhe um contorno voltado ao campo da fenomenologia "[...] a hermenêutica é o exame de condições em que ocorre a compreensão". Ricoeur the atribui o papel da "[...] mediação de uma interpretação" (MORA, 1996, p. 333). Assim, fica mais claro entendê-la como a ciência maior da interpretação dos significados e, portanto, o primeiro e fundamental traço da representação.

\section{REPRESENTAÇÃO E CONTEXTO DIGITAL}

Logo depois do pós-guerra, o cientista Vanevar Bush propôs uma solução para o crescente volume de informações geradas, oriundo, em grande parte, das inovações e estratégias produzidas ao longo do esforço de guerra. A tarefa proposta era um brutal esforço de organização. A solução imaginada por Bush foi o uso das primeiras e incipientes tecnologias de processamento eletrônico, para duplicar os esforços mentais do homem (OLIVEIRA, 2003). Algum tempo depois, Paul Otlet e Henry de La Fontaine criaram a 
Documentação, propondo uma espetaculares e preocupantes são sistematização do massivo acervo disperso questões que vão além do processamento, das informações até então disponíveis, tratamento, armazenagem e recuperação. criando, assim, as bases da Ciência da Permanecem como uma das grandes Informação, dentro do conceito da interrogações do ser da Sociedade da Documentation (ORTEGA, 2004). A Informação, algo que precede a tudo isso: literatura é pródiga em elogiar a forma como representar, de forma mais fiel como enfrentaram, com criatividade e possível, o que observamos, conhecemos eficiência, a magnitude do problema da organização, tratamento, indexação e recuperação da informação. Hoje, com certeza, estamos diante de outro desafio quantitativo da informação, diferente daquele com que se depararam Bush, Otlet e Fontaine. As informações e suas representações são criadas de forma alucinante e ocupam milhões de exabytes. Segundo a IDC - Internet Data Corporation (INTERNATIONAL DATA CORPORATION - IDC, 2007):

1 O montante de informação digital produzida em 2006 equivaleria a 6 toneladas de livros para cada habitante da terra, ou seja, um elefante digital

2 Se imprimíssemos tudo o que foi produzido digitalmente no ano passado, haveria papel suficiente para embrulhar a terra quatro vezes.

Apesar de todos os esforços no sentido de desenvolver instrumentos, metodologias e tecnologias $o$ que realmente emerge desses números e registramos? E se dada uma resposta convincente a esta questão maior, surge outra: podemos esperar que as tecnologias e a capacidade criativa dos trabalhadores da informação se encarregarão de operacionalizá-la? O sucesso de toda a parafernália digital depende da compreensão profunda dos aspectos envolvidos nos processos representacionais. E essas questões parecem estar amortecidas, obnubiladas pela visão excessivamente instrumental e tecnológica que impera no contexto atual.

\section{REFERÊNCIAS}

ABRÃO, Bernadette Siqueira. História da filosofia. São Paulo: Nova Cultual, 1999.

ALVARENGA, Lídia. Representação da informação e do conhecimento na perspectiva da ciência da informação em tempo e espaços digitais. Revista Eletrônica de Biblioteconomia em Ciência da Informação, Florianópolis, n. 15, 1.

Sem. 2003. Disponível em: $<$ http://redalyc.uaemex.mx/redalyc/pdf/147/ 14701503.pdf>. Acesso em: 25 abr. 2007.

BOSON, Gerson B. Filosofia do direito: interpretação antropológica. 2. ed. Belo 
Horizonte: Del Rey, 1996.

CAGLIARI, Luiz Carlos. A origem do alfabeto. Disponivel em:

$<$ www.dalete.com.br/saber/origem.pdf>.

Acesso em: 20 abr. 2007.

CALANDRI, Filippo. De Arithmetica.

Florença: Lorenzo Morgiani e Johannes Petri, 1491.

CAPURRO, Rafael. Epistemologia y ciencia da la informacion. In: ENCONTRO NACIONAL DE PESQUISA EM CIÊNCIA DA INFORMAÇÃO, 5, 2003, Belo Horizonte. Anais... Belo Horizonte:

Escolada Ciência da Informação da UFMG, 2003. Disponível em:

<http://www.capurro.de/enancib_p.htm>. Acesso em: 15 abr. 2007.

CHAUÍ, Marilena. Convite à filosofia. São Paulo: Martins Fontes, 1997.

CHAUÍ, Marilena. Introdução à história da Filosofia: dos pré-socráticos a Aristóteles. São Paulo: Brasiliense, 1994. v.1, 390 p.

CORNELIUS, Ian. Theorizing Information for Information Science. Annual Review of Information science and Technology, White Plains, v. 36, p. 393-425, 2002.

GADAMER, Hans-Georg. Verdade e método: fundamentos de uma hermenêutica filosófica. 3. ed. Petrópolis: Vozes, 2001.

HAMILTON, Edith. Mitologia. São Paulo: Martins Fontes, 1992.

\section{INTERNATIONAL DATA CORPORATION} - IDC. The expanding digital universe 2007. Disponível em: <http://www.emc.com/about/destination/digi tal_universe/pdf/Expanding_Digital_Univers e_IDC_WhitePaper_022507.pdf>. Ācesso em: 12 maio 2007.

LÖWY, Michael. Ideologias e ciência social: elementos para uma análise marxista. 16. ed. São Paulo: Cortez, 2003
MAN, John. A história do alfabeto: como 26 letras transformaram o mundo ocidental. Rio de Janeiro: Ediouro, 2002.

MORA, José Ferrater. Dicionário de filosofia. 2. ed. São Paulo: Martins Fontes, 1996.

OLIVEIRA, Marlene. As pequenas e médias empresas e a gestão da Informação. In: PAIM, Isis (Org.). A gestão da informação e do conhecimento. Belo Horizonte: UFMG, 2003. p. 9-28.

ORTEGA, Cristina Dotta. Relações entre biblioteconomia, documentação e ciência da informação. DataGramaZero: Revista de Ciência da informação, Rio de janeiro, v. 5 , n. 5 , out.2004. Disponível em: <http://dgz.org.br/out04/F_I_aut.htm>. Acesso em: 05 maio 2007.

SHANNON, Claude E.; WEAVER, Warren. A teoria matemática da comunicação. São Paulo: DIFEL, 1975.

SOUZA, Renato Rocha. Uma proposta de metodologia para a escolha automática de descritores, utilizando sintagmas nominais. 2005. Tese (Doutorado em Ciência da Informação) - Escola de Ciência da Informação, Universidade Federal de Minas Gerias, Belo Horizonte.

\section{Title}

Knowledge's representation: history, feelings and perception.

\begin{abstract}
This article intends to show and develop some ideas about what lies behind the knowledge representation, considering that the vast majority of the informational processes depend on some kind of representation. It aims to present some ideas about the many aspects
\end{abstract}


involved in this process through the analysis of the theorical and historical contributions about the different human manners to represent the world, the feelings and perceptions related to its life's environment.

\section{Keywords}

Knowledge representation. Information processes. Knowledge communication.

\section{Título}

Representación del conocimiento: historia, sentimiento y la percepción.

\section{Resumen}

El artículo tiene el objectivo de destacar y desarrollar algunas ideas acerca de lo que subyace en la representación del conocimiento, teniendo en cuenta que casi todos los procesos de información dependen de los procesos de representación. Presenta una reflexión sobre algunos de los elementos que componen el proceso en cuestión desde el análisis histórico de las contribuciones teóricas sobre las formas de representar el mundo humano en que viven $y$ de sus sentimientos y percepciones sobre esta.

\section{Palabras Clave}

Representación del conociminto. Procesos de información. Comunicación del conocimiento.

Recebido em: 05.05.2008

Aceito em: 09.02.2009 